\title{
Pengaruh Temperatur Sintering Terhadap Komposisi, Sifat Magnetik dan Absorpsi Gelombang Mikro Komposit Nano Zinc-Ferit
}

\author{
L. Rifiana Dewi, W. Widanarto*, M. Effendi \\ Jurusan Fisika, Fakultas Matematika dan Ilmu Pengetahuan Alam, \\ Universitas Jenderal Soedirman, Purwokerto \\ Jl. Dr. Soeparman No 16 Karangwangkal Purwokertoe \\ *e-mail: wahyu.widanarto@unsoed.ac.id
}

\begin{abstract}
Abstrak- Material penyerap gelombang mikro mempunyai peran penting dalam perkembangan teknologi antiradar, anti-electromagnetic interference dan komunikasi tanpa kabel. Pembuatan komposit nano zn-ferit dilakukan menggunakan metode reaksi padatan dengan komposisi $80 \mathrm{Fe}_{3} \mathrm{O}_{4}: 20 \mathrm{ZnO}$ dalam persen mol dan pengaruh medan magnet luar. Zn-Ferit disintering pada temperatur 500, 800 dan $1100{ }^{\circ} \mathrm{C}$. Karakterisasi struktur, sifat magnetik dan absorpsi gelombang mikro pada ferit dilakukan masing-masing menggunakan XRD, VSM dan VNA. Hasil karakterisasi menunjukkan bahwa intensitas fasa nano kristal $\mathrm{ZnFe}_{2} \mathrm{O}_{4}$ yang terbentuk meningkat dengan peningkatan temperatur sintering. Sifat magnetik yang meliputi magnetisasi remanen $\left(M_{r}\right)$ dan magnetisasi saturasi $\left(M_{s}\right)$ mengalami penurunan, sedangkan medan koersivitas $\left(H_{c}\right)$ mengalami peningkatan dengan meningkatnya temperatur sintering. Ferit yang disintering pada $800{ }^{\circ} \mathrm{C}$ menujukkan performa yang baik dengan ditandai nilai reflection loss $\left(R_{L}\right)$ sebesar $-69 \mathrm{~dB}$ pada frekuensi $16,9 \mathrm{GHz}$.
\end{abstract}

Kata Kunci: Ferit alam, Zinc, komposit, sifat magnetik, reflection loss

\begin{abstract}
Microwave absorbent material has an important role in the development of anti-radar technology, anti-electromagnetic interference and wireless communication. Zn-ferrite nano composites was synthetized using the solid-state reaction method with a composition of $80 \mathrm{Fe}_{3} \mathrm{O}_{4}: 20 \mathrm{ZnO}$ in mol percent and the influence of the external magnetic field. Zn-ferrites ware sintered at temperatures of 500, 800 and $1100^{\circ} \mathrm{C}$. Characterizations of the structure, magnetic properties and absorption of microwaves on ferrite were carried out using XRD, VSM and VNA respectively. The characterization results showed that the intensity of the nano phase crystals $\mathrm{ZnFe}_{2} \mathrm{O}_{4}$ formed increased with increasing sintering temperature. Magnetic properties which include remanent magnetization $\left(M_{r}\right)$ and saturation magnetization $\left(M_{s}\right)$ decreased, while the coercivity field $\left(H_{c}\right)$ increased with increasing sintering temperature. Synthesized ferrite at $800{ }^{\circ} \mathrm{C}$ showed good performance with a reflection loss $\left(R_{L}\right)$ value of $-69 \mathrm{~dB}$ at a frequency of $16.9 \mathrm{GHz}$.
\end{abstract}

Key words: Natural ferrite, zinc, composite, magnetic properties, reflection loss

\section{PENDAHULUAN}

Magnetit $\left(\mathrm{Fe}_{3} \mathrm{O}_{4}\right)$ menjadi bahan kajian yang menarik perhatian para ahli dalam bidang teknologi nano karena memiliki peluang aplikasi yang luas pada bidang industri seperti keramik, katalis, energy storage, magnetic data storage, ferofluida, diagnosis medis, bahan penyerap radar (radar absorbing material) maupun bahan pelindung interferensi gelombang elektromagnetik [1]. Magnetit $\left(\mathrm{Fe}_{3} \mathrm{O}_{4}\right)$ memiliki sifat soft magnetic, dan untuk RAM membutuhkan material yang memiliki sifat soft magnetic. Kriteria untuk suatu material menjadi bahan penyerap gelombang mikro yaitu memiliki sifat magnetik dan sifat listrik. Untuk sifat magnetik dibutuhkan material yang bersifat soft magnetic, sedangkan untuk sifat listrik dibutuhkan material yang memiliki nilai konduktifitas listrik yang tinggi. Untuk mendapatkan sifat dari keduanya maka dilakukan pendopingan dari dua unsur yang berbeda. Unsur yang pertama diharapkan dapat memenuhi kriteria dari sifat kemagnetannya, sedangkan unsur yang kedua diharapkan dapat memenuhi kriteria dari sifat kelistrikannya, sehingga nantinya material baru tersebut dapat diaplikasikan sebagai bahan penyerap radar. Unsur yang biasanya digunakan untuk memenuhi kriteria sifat kelistrikan adalah $\mathrm{Ti}, \mathrm{Zn}, \mathrm{Mn}, \mathrm{Ni}, \mathrm{Co}$, dan lain-lain. Efek yang dapat ditimbulkan dari penambahan unsur tersebut misalnya, variasi kapasitas panas dan konduktifitas yang telah ditujukan untuk aplikasi magnetik [2]. 
Berdasarkan data yang diperoleh diketahui bahwa tidak terdapat hubungan linier antara peningkatan temperatur sintering terhadap nilai reflection loss.

Berdasarkan penjelasan di atas, material penyerap gelombang mikro dibuat dengan memanfaatkan oksida ferit $\left(\mathrm{Fe}_{3} \mathrm{O}_{4}\right)$ yang dimodifikasi dengan $\mathrm{ZnO}$ melalui metode reaksi padatan pada temperatur sintering yang berbeda. Material $\mathrm{Fe}_{3} \mathrm{O}_{4}$ diperoleh dari ekstraksi ferit alam yang berasal dari Desa Widara payung Kecamatan Binangun Kabupaten Cilacap, karena pasir di daerah tersebut mengandung 70\% mineral berupa magnetit $\left(\mathrm{Fe}_{3} \mathrm{O}_{4}\right)$ [3]. Zinc Oxide memiliki sifat konduktivitas panas yang tinggi sehingga membuat material tersebut tepat diaplikasikan sebagai bahan penyerap radar (radar absorbing material). Temperatur sintering yang sangat tinggi harus dihindari karena untuk menjaga fasa dari $\mathrm{Fe}_{3} \mathrm{O}_{4}$ agar tidak berubah.

\section{METODE}

Proses pembuatan material zinc ferite dimulai dengan menggerus $24 \mathrm{~g} \mathrm{Fe}_{3} \mathrm{O}_{4}$ dan $6 \mathrm{~g} \mathrm{ZnO}$ menggunakan HEM (High Energy Milling). Penggerusan dilakukan secara basah (wet milling) dengan menggunakan aquades. Kemudian sampel dipanaskan menggunakan hot-plate dan diaduk magnetic stirrer sampai berbentuk serbuk kembali. Sampel dikalsinasi dengan temperatur $500{ }^{\circ} \mathrm{C}$ dengan holding time 1 (satu) jam. Setelah itu, PVA ditambahkan sampel sebagai bahan perekat dan dipanaskan lagi sampai sampel berbetuk serbuk kembali. Sampel dimampatkan dan dicetak pada tekanan 1 satu ton dalam pengaruh medan magnet luar. Sampel yang sudah dikompasi selanjutnya disintering dengan tiga variasi temperatur yaitu 500, 800 dan $1100{ }^{\circ} \mathrm{C}$ Setiap temperatur diberi holding time selama 3 jam dan pada proses pendinginan menggunakan proses cooling furnace. Sampel yang telah dipanaskan ditandai dengan kode $\mathrm{ZF}$ 1, ZF2 dan ZF3 masing-masing untuk temperatur 500, 800 dan $1100{ }^{\circ} \mathrm{C}$

\section{HASIL DAN PEMBAHASAN \\ A. Struktur Kristal}

Gambar 1 menunjukkan hasil karakterisasi XRD dari $\mathrm{Fe}_{3} \mathrm{O}_{4}$ yang didoping dengan $\mathrm{ZnO}$ dengan variasi temperatur sintering yang berbeda-beda. Sampel pertama yaitu sampel
$\mathrm{ZF}$ 1, fasa yang terbentuk masih berupa zinc oxide $(\mathrm{ZnO})$ dan magnetite $\left(\mathrm{Fe}_{3} \mathrm{O}_{4}\right)$, hal ini menunjukkan bahwa dengan temperatur 500 ${ }^{\circ} \mathrm{C} \mathrm{ZnO}$ belum bereaksi dengan $\mathrm{Fe}_{3} \mathrm{O}_{4}$. Menurut penelitian Mastuki dkk pada 2012, transformasi fasa dari magnetite menjadi hematite terjadi pada temperatur $<500{ }^{\circ} \mathrm{C}$. Fasa hematite mulai terbentuk pada temperatur $>320{ }^{\circ} \mathrm{C}$ sampai temperatur tinggi. Transformasi fasa menjadi hematite berjalan lambat sampai temperatur $<450{ }^{\circ} \mathrm{C}$. Pada suhu $500{ }^{\circ} \mathrm{C}$ akan tercipta inti hematite dan akan tumbuh menjadi fasa hematite dengan cepat. Pembentukan fasa ini sangat cepat pada temperatur $>520 \quad{ }^{\circ} \mathrm{C}$ yaitu sekitar $70-90 \%$ sampel akan menjadi fasa hematite dalam waktu 60 menit.

Sampel kedua yaitu sampel ZF2 terbentuk fasa hematite $\left(\mathrm{Fe}_{2} \mathrm{O}_{3}\right)$ dan zinc iron oxide $\left(\mathrm{ZnFe}_{2} \mathrm{O}_{4}\right)$, hal ini menunjukkan pada temperatur $800{ }^{\circ} \mathrm{C} \mathrm{ZnO}$ sudah bereaksi dengan $\mathrm{Fe}_{3} \mathrm{O}_{4}$ walaupun belum bereaksi secara sempurna Pada temperatur ini terlihat fasa magnetite telah berubah menjadi fasa hematite, ini dikarenakan pengaruh temperatur sintering yang digunakan $>520{ }^{\circ} \mathrm{C}$. Sampel yang terakhir yaitu sampel $\mathrm{ZF} 3$ fasa yang terbentuk adalah hematite $\left(\mathrm{Fe}_{2} \mathrm{O}_{3}\right)$ dan zinc iron oxide $\left(\mathrm{ZnFe}_{2} \mathrm{O}_{4}\right)$. Terlihat bahwa fasa zinc iron oxide $\left(\mathrm{ZnFe}_{2} \mathrm{O}_{4}\right)$ lebih banyak terbentuk dibanding dengan fasa hematite $\left(\mathrm{Fe}_{2} \mathrm{O}_{3}\right)$, artinya pada temperatur sintering $1100{ }^{\circ} \mathrm{C}$ sebagian besar $\mathrm{ZnO}$ dan $\mathrm{Fe}_{3} \mathrm{O}_{4}$ sudah bereaksi walaupun belum sempurna.

Transformasi fasa yang terjadi pada setiap temperatur sintering dipengaruhi oleh ukuran partikel kristalit. Ukuran partikel ini yang nantinya memperlihatkan tingkat homogenitas saat proses pencampuran. Perhitungan ukuran kristal menggunakan metode Debye-Scherrer.

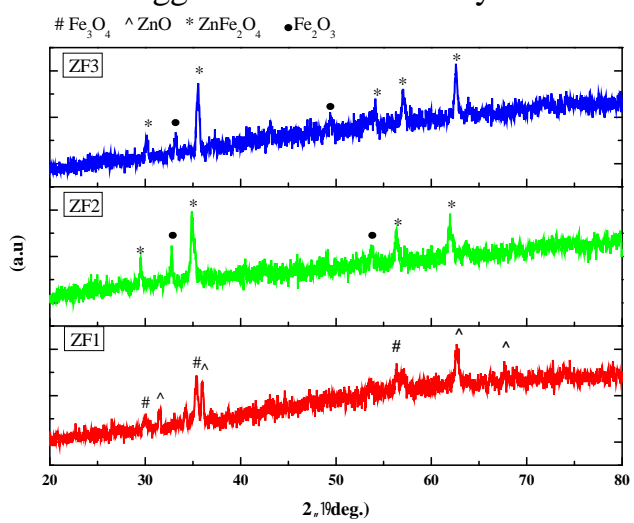

Gambar 1. Pola difraksi komposit nano Zn-ferit alam yang disintering pada temperatur 500,800 dan $1100{ }^{\circ} \mathrm{C}$ 
Tabel 1. Ukuran partikel kristalit

\begin{tabular}{ccrr}
\hline Sampel & $\begin{array}{c}2 \theta \\
(\mathrm{deg})\end{array}$ & FWHM & $\begin{array}{c}\text { Ukuran Kristal } \\
(\mathrm{nm})\end{array}$ \\
\hline ZF1 & 35,34 & 0,35 & 25,1 \\
& 35,93 & 0,23 & 38,7 \\
& 56,26 & 1,01 & 9,3 \\
& 62,67 & 0,29 & 33,9 \\
ZF2 & 29,51 & 0,13 & 66,7 \\
& 32,78 & 0,13 & 67,8 \\
& 34,86 & 0,42 & 20,6 \\
& 61,79 & 0,46 & 20,9 \\
ZF3 & 35,48 & 0,33 & 26,8 \\
& 57,01 & 0,33 & 28,7 \\
& 62,57 & 0,28 & 35,1 \\
\hline
\end{tabular}

terlihat bahwa sampel ZF3 memiliki ukuran partikel kristalin terkecil yaitu sekitar 26,8$35,1 \mathrm{~nm}$. Sampel nanopartikel dengan ukuran butir yang lebih kecil memiliki respon magnetik yang lebih tinggi dibandingkan dengan sampel nanopartikel dengan ukuran butir yang lebih besar. Hal tersebut disebabkan semakin kecil ukuran butir partikel maka momen magnetik pada nanopartikel cenderung lebih tidak stabil. Ketidakstabilan momen magnetik pada partikel dengan ukuran butir yang lebih kecil disebabkan oleh energi anisotropi yang dimiliki oleh partikel tersebut jauh lebih kecil, akibatnya bila terdapat medan magnet eksternal yang mempengaruhi maka momen magnetik pada nanopartikel dengan ukuran butir yang lebih kecil akan memberikan respon yang lebih cepat [4].

\section{B. Sifat Magnetik}

Sifat magnetik komposit Zn-Ferit digambarkan dengan kurva hysteresis seperti terlihat dalam Gambar 2. Sifat magnetik komposit berubah seiring dengan peningkatan temperatur sintering. Pada Tabel 2 menunjukkan nilai $M_{r}$ dan $M_{s}$ mengalami penurunan, sedangkan nilai $\mathrm{Hc}$ mengalami peningkatan. Hal ini dikarenakan pada temperatur sintering $1100{ }^{\circ} \mathrm{C}$ ukuran partikel kristal lebih kecil dibanding pada temperatur 500 dan $800{ }^{\circ} \mathrm{C}$. Faktor ukuran partikel kristal memberikan pengaruh yang sangat signifikan terhadap sifat-sifat magnet. Nilai $H_{c}$ dipengaruhi oleh kemurnian bahan baku, dan ukuran kristal yang berperan dalam menghambat pergerakan dinding domain. Semakin kecil ukuran kristal berarti semakin banyak batas antar kristal dan semakin banyak penghalang pergerakan dinding domain sehingga ketahanan terhadap medan demagnetisasi semakin besar yang berarti harga $H_{c}$ semakin tinggi [5]. Penurunan nilai $M_{r}$ dan $M_{s}$ dipengaruhi oleh fasa yang terbentuk. Saat temperatur sintering $500{ }^{\circ} \mathrm{C}$ fasa yang terbentuk masih $\mathrm{Fe}_{3} \mathrm{O}_{4}$ (magnetit), fasa ini yang menyebabkan nilai $M_{r}$ dan $M_{s}$ tinggi karena mendekati sifat super paramagnetic. Saat temperatur sintering 800 dan $1100{ }^{\circ} \mathrm{C}$ fasa $\mathrm{Fe}_{3} \mathrm{O}_{4}$ (magnetit) sudah bertransformasi menjadi $\alpha-\mathrm{Fe}_{2} \mathrm{O}_{3}$ (hematit), hal ini yang menyebabkan penurunan nilai $M_{r}$. $M_{s}$ tidak terjadi disebabkan karena $\alpha-\mathrm{Fe}_{2} \mathrm{O}_{3}$ (hematit) bersifat diamagnetic [6].

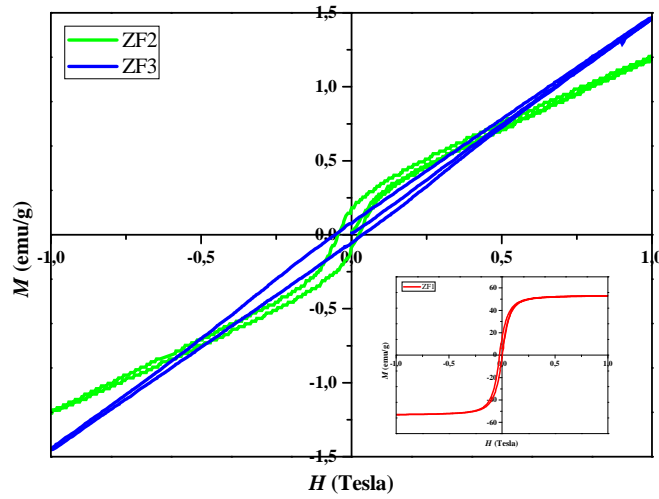

Gambar 2. Kurva histeresis magnetik komposit nano Zn-Ferit yang disintering pada temperatur 500, 800 dan $1100^{\circ} \mathrm{C}$

Tabel 2 Tabel perbandingan nilai $M_{r}, H_{c}, M_{s}$, dan $H_{\text {maks }}$

\begin{tabular}{crrrrr} 
Sampel & $\begin{array}{c}M_{r} \\
(\mathrm{emu} / \mathrm{g})\end{array}$ & $\begin{array}{c}H_{c} \\
(\mathrm{Tesla})\end{array}$ & $\begin{array}{c}M_{s} \\
(\mathrm{emu} / \mathrm{g})\end{array}$ & \multicolumn{1}{c}{$\begin{array}{c}H_{\text {maks }} \\
\text { (Tesla) }\end{array}$} \\
\cline { 1 - 3 } ZF1 & 10,02 & 0,015 & 50,00 & 0,388 \\
ZF2 & 0,05 & 0,045 & 0,42 & 1,000 \\
ZF3 & 0,047 & 0,067 & 0,23 & 1,000 \\
\hline
\end{tabular}

\section{Absorpsi Gelombang Mikro}

Pengujian absorpsi atau penyerapan gelombang mikro dilakukan untuk mengetahui nilai reflection loss $\left(R_{L}\right)$ sebagai fungsi frekuensi gelombang mikro seperti terlihat dalam Gambar 3. Sampel ZF2 merupakan sampel yang memiliki daya serap paling tinggi yaitu $-69 \mathrm{~dB}$ yang terjadi pada frekuensi 16,9 GHz. Berdasarkan nilai $R_{L}$ menunjukkan bahwa material komposit nano Zn-Ferit dengan temperatur sintering $800 \quad{ }^{\circ} \mathrm{C}$ merupakan material yang paling optimum menyerap gelombang mikro dibandingkan dua sampel lainnya. Semakin rendah nilai $R_{L}$ maka semakin besar daya serap bahan terhadap gelombang mikro [7]. Dilihat dari sifat magnetik bahan, syarat suatu material untuk dapat diaplikasikan sebagai penyerap gelombang mikro yaitu nilai permeabilitas yang tinggi, koersifitas rendah dan saturasi 
tinggi. Bila ketiga sampel dibandingkan maka seharusnya sampel ZF1 yang memiliki nilai $R_{L}$ tertinggi diantara sampel lainnya. Namun demikian tidak terdapat hubungan linier antara peningkatan temperatur sintering terhadap nilai $R_{L}$.

Berdasarkan nilai $R_{L}$, secara umum ketiga sampel dapat digunakan sebagai material penyerap gelombang mikro dengan pengaplikasiannya yang berbeda-beda. Hal ini disebabkan karena masing-masing sampel memiliki absorpsi maksimum pada frekuensi tertentu dalam rentang frekuensi gelombang mikro [8].

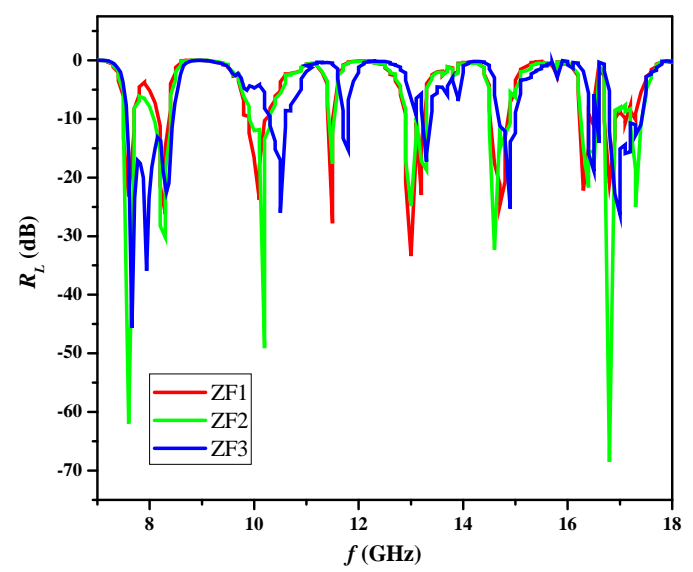

Gambar 3. Reflection loss $\left(R_{L}\right)$ sebagai fungsi frekuensi komposit nano $\mathrm{Zn}$-Ferit yang disintering pada temperatur 500,800 dan $1100{ }^{\circ} \mathrm{C}$

\section{KESIMPULAN}

Modifikasi material oksida ferit telah dilakukan dengan memasukkan ion-ion $\mathrm{Zn}^{2+}$ dalam strukturnya melalui proses solid-state reaction pada temperatur yang bervariasi. Spektrum difraksi didominasi oleh puncak puncak difraksi kristal $\mathrm{ZnFe}_{2} \mathrm{O}_{4}$ seiring dengan meningkatnya temperatur sintering. Sifat magnetik yang meliputi magnetisasi remanen $\left(M_{r}\right)$ dan magnetisasi saturasi $\left(M_{s}\right)$ mengalami penurunan, sedangkan medan koersivitas $\left(H_{c}\right)$ mengalami peningkatan dengan meningkatnya temperatur sintering. Sampel ZF2 mempunyai kemapuan yang baik dalam menyerap gelombang mikro pada frekuensi 7 sampai 18 $\mathrm{GHz}$ dengan nailai $R_{L}$ tertinggi sebesar $-69 \mathrm{~dB}$ pada frekuensi $16,9 \mathrm{GHz}$.

\section{UCAPAN TERIMA KASIH}

Penulis mengucapkan terima kasih kepada Universitas Jenderal Soedirman yang telah memberikan dukungan finansial dan fasilitas laboratorium.

\section{DAFTAR PUSTAKA}

[1] H.W. Wang, S.C. Kung, Crystallization of nano-sized Ni-Zn ferrite powders prepared by hydrothermal method, Joural Magn. Magn. Mater. 270 (2004).

[2] R. Agustianto, Widyastuti, Pengaruh dopan Co-Zn dengan variasi fraksi mol dan variasi ph terhadap sifat magnetik dan struktur mikro barium heksaferit dengan metode sol-gel auto combustion, J. Tek. Pomits. 3 (2014).

[3] W. Widanarto, M.R. Sahar, S.K. Ghoshal, R. Arifin, M.S. Rohani, K. Hamzah, Effect of natural $\mathrm{Fe}_{3} \mathrm{O}_{4}$ nanoparticles on structural and optical properties of $\mathrm{Er}^{3+}$ doped tellurite glass, J. Magn. Magn. Mater. $326 \quad$ (2013) 123-128. doi:10.1016/j.jmmm.2012.08.042.

[4] P.A. Guimaraes, Prinsiples of Nanomagnetism, Springer, German, 2009.

[5] I.N. Saidah, M. Zainuri, Pengaruh variasi $\mathrm{pH}$ pelarut $\mathrm{HCl}$ pada sintesis Barium MHeksaferrit dengan doping $\mathrm{Zn}$ $\left(\mathrm{BaFe}_{11,4} \mathrm{Zn}_{0,6} \mathrm{O}_{19}\right)$ menggunakan metode kopresipitasi, J. Sains Dan Seni ITS. 1 (2012).

[6] W. Widanarto, M. Jandra, S.K. Ghoshal, M. Effendi, W.T. Cahyanto, $\mathrm{BaCO}_{3}$ mediated modifications in structural and magnetic properties of natural nanoferrites, J. Phys. Chem. Solids. 79 (2015) 78-81. doi:10.1016/j.jpcs.2014.12.011.

[7] S.. Phang, M. Tadakoro, J. Watanabe, N. Kuramoto, synthesis characterization and microwave absorption property of doped polyaniline nanocomposites containing $\mathrm{TiO}_{2}$ nanoparticles and carbon nanotubes, Synt. Met. 158 (2008).

[8] S.H. Hosseini, S.H. Mohseni, A. Asadnia, H. Kerdari, Synthesis and microwave absorbing properties of polyaniline $/ \mathrm{MnFe}_{2} \mathrm{O}_{4}$ nanocomposite, $\mathrm{J}$. Alloys Compd. 509 (2011) 4682-4687. doi:10.1016/j.jallcom.2010.11.198. 